\title{
RECENT ADVANCES IN ENDOCRINOLOGY
}

\author{
RUTH H. ST. JOHN, M.D., \\ Department of Medicine, The Ohio State University
}

THYROID

In reviewing the matter of endocrine advances during the past year or two, it seems evident that the discovery and subsequent clinical use of Thiourecil is the outstanding achievement. Since the original use of the drug by Astwood and his associates in 1943 (1) much interest has centered on the question of what ultimate value Thiouracil would have in the treatment of thyroroxicosis. Considerable skepticism was expressed in the early stages of its use, (2) and conflicting reports of its efficacy have been published during the last few months. Two and a half years have now elapsed since the first use of the drug, and in January of this year a comprehensive report was published by Robert $H$. Williams (3) giving the effect of prolonged treatment and the toxic reactions observed in 247 patients treated in the Harvard Medical School Clinics. Briefly, it appears to be established that Thiouracil in doses varying from $.6 \mathrm{gm}$. to $.3 \mathrm{gm}$. daily will produce remissions in patients with thyrotoxicosis; that thyroidectomy is accompanied by less thyrotoxic reactions when Thiouracil is used, even though the gland is rendered more vascular and friable than with the use of iodides; that combined administration of Thiouracil and iodides is desirable; and that toxic reactions may be expected in 14 per cent of cases. Toxic reactions are found to be more common with prolonged use of the drug and when unnecessarily large doses are used. Most important in the long list of toxic manifestations are leucopenia, agranulocytosis, fever, and various anaphylactic reactions. It has been suggested that the body capacity to bind protein is responsible for the anaphylactic reactions as well for the actual therapeutic effect of the drug (4). Work is rapidly going ahead in the perfection of new anti-thyroid drugs for which hope of non-toxicity is held-and only time will tell to what extent these drugs may supersede surgery in the treatment of thyrotoxicosis.

\section{PANCREAS}

Efforts have been centered on improvement of diabetic control by producing insulin preparations which will answer the 24-hour requirement. Protamine-zinc 
insulin was thought to be the answer to this, but only in mild cases requiring less than 40 units daily has it been possible to rely on protamine to prevent hyperglycemia during the day, without producing hypoglycemia during the night.

A mixture of regular or crystalline insulin and protamine-zinc insulin in the ratio of $1: 3$ has been quite satisfactory, but is impractical from the standpoint of the ease of administration.

Globin-zinc and histone-zinc preparations have been tried with disappointing results.

In recent months, however, experiments have been made using a bi-phasic insulin containing twenty-five per cent of the protamine in quickly absorbable form, and seventy-five per cent in the present slowly absorbable precipitated form. It is uncertain as yet whether or not this form will prove to be stable for marketable use (7), (8).

\section{MALE HYPOGONADISM}

The male climacteric and sterility in the male have received a great deal of attention during these past months. Carl G. Heller has contributed immensely to the understanding of male hypogonadism by his comprehensive classification of the various forms of testicular failure (9). His is one of several excellent reviews of the problem published in the last two years. There is increasing interest in the use of testicular biopsies as an aid in therapeutic evaluation of problems of hypogonadism. Patients having complete hyalinization of seminiferous tubules with partial Leydig-cell failure may be expected to respond favorably to treatment with androgenic substitution therapy, whereas such patients would be totally unresponsive to chorionic or pituitary gonadotropins from the standpoint of subjective clinical relief of symptoms. It is to be understood that spermatogenesis cannot be attained when complete hyalinization has occurred.

In patients demonstrating only an early sclerotic change in the seminiferous tubules, with partial Leydig-cell failure, there is reason to hope that spermatogenesis may be stimulated by the use of chorionic gonadotropins. The duration and expense of both androgenic and gonadotropic therapy are of sufficient importance to justify the wider use of testicular biopsies as an aid in therapeutic prognosis.

Since mumps orchitis is of such significance as a cause of sterility and of early climacteric changes, interesting work is being done regarding its prevention. Gamma globulin from mumps convalescent serum is proving effective in some cases (10).

\section{ADRENAL}

Of practical importance from a diagnostic standpoint are the favorable reports concerning the reliability of the Kepler test in Addison's disease (11). Further studies have been made to determine the cause of faulty diuresis and the electrolyte changes which are the basis for the test (12), in the hope that the diagnostic measures may be further improved.

It is highly desirable to be able to discard a test such as the original Wilder test involving salt deprivation which was attended by dangerous reactions.

\section{STEROIDS}

The literature in recent months has been laden with reports of the painstaking efforts to isolate and differentiate the various androgenic steroids excreted in the urine (13), (14). It is thought that increasing simplification of methods of extraction and increasing knowledge of the source of the various fractions will prove to be extremely valuable in the diagnosis of adrenal and gonadal pathology. Abnormalities in which dependence for diagnosis is placed on the 17-ketosteroids, include adrenal deficiency in male and females, hirsutism, virilism, amenorrhea, and obesity in females, precocious puberty in males and females, adrenal cortical 
tumor, gonadal tumors, and cancer in areas not associated with an endocrine gland.

Pregnandiol excretion in the urine during prolonged amenorrhea is being urged as a rapid, simple test for pregnancy (15). This method of testing was advocated as early as 1931 , but has not come into wide use due to difficulties encountered in laboratory techniques. It is not yet certain whether or not the method is sufficiently accurate to justify its use.

\section{PITUITARY}

Continued efforts are being made to isolate and purify the various anterior pituitary hormones, but outstanding progress has not yet been achieved.

\section{FEMALE HYPOGONADISM}

Menstrual disorders, and sterility are still the outstanding problems in this field. In the last two years, there has been a better understanding of the importance of cyclic therapy in secondary amenorrhea and cases of sustained follicle hyperplasia. The uses of testosterone and progesterone are better understoodand there is a gradual and fortunate trend away from the indiscriminate use of estrogens.

Improved pituitary gonadotropins will eventually fill a great need for physiological ovarin stimulation.

Vaginal smears, stained by specific dyes, are now being widely used as a means of differentiating the various degrees of epithelial cell growth in response to estrogen hormone elaboration. This procedure has provided a practical and simple diagnosis test which may be used in an office.

\section{BIBLIOGRAPHY}

1. Astwood, E. B. Thiouracil treatment in hyperthyroidism. Jr. Clin. Endocrinol., 4: 229-248, 1944.

2. Loskin, S., and Levine, R. Recent advances in physiology of the thyroid and their clinical application. Arch. Int. Med., 74: 375, 1944.

3. Williams, Robt. H. Thiouracil treatment of thyrotoxicosis I and II. Jr. Clin. Endocrinol., 6: 1-51, 1946.

4. McArthur, Janet W., Rawson, R. W., and Means, J. H. Idiosyncratic Febrile Reactions to Thiouracil. Ann. of Int. Med., 23: 6: 915, Dec., 1945.

5. McCullagh, E. Perry. Present Status of Thiouracil. Cleve. Clin. Quart., 13: 56-66, April, 1946.

6. Crile, George, Jr., and Dinsmore, R. S. Present Status of Surgical Treatment of Hyperthyroidism. Cleve. Clin. Quart., 13: 50-56, April, 1946.

7. MacBryde, C. M., and Reiss, R. Modified Protamine-zinc insulin. Jr. Clin. Endocrinol., 4: 469-479, Oct., 1944.

8. MacBryde, C. M. (Editorial) Improved forms of Insulin. Jr. Clin. Endocrinol., 5: 189-191, April, 1945.

9. Heller, Carl G., and Nelson, W. O. Hyalinization of Seminiferous Tubules associated with normal or failing Leydig-cell function (3 articles). Jr. Clin. Endocrinol., 5: 1-33, Jan., 1945 .

10. Gellis, Sidney S., McGuinness, Aims C., and Peters, Michael. Study on prevention mumps orchitis by gamma globulin. Am. Jr. Med. Sc., 210: 5-661, Nov.,1945.

11. Robinson, F. J., Power, M. H., and Kepler, E. J. Two new procedures to assist in recognition and exclusion of Addison disease. Proc. Staff Meet., Mayo Clinic, 16: 577, 1941.

12. Reforzo-Membrives, Juan, Power, M. H., and Kepler, E. J. Studies on renal excretion of water and electrolytes in cases of Addison's disease. Jr. Clin. Endocrinol., 5: 76-85, Feb., 1945.

13. Salter, W. T., Cahen, R. L., and Sappington, T. S. Urinary 17-Ketosteroids. Jr. Clin. Endocrinol., 6: 52-76, Jan., 1946.

14. Pincus, Gregory. Analysis of Human Urines for Steroid Substances. Jr. Clin. Endocrinol., 5: 291-3.0, Sept., 1945.

15. Guterman, Henry $S$. Further observations on the value of the pregnandiol test for pregnancy. Jr. Clin. Endocrinol., 5: 407-411, Dec., 1945. 